\title{
Effect of co-ingestion of fat on the metabolic responses to slowly and rapidly absorbed carbohydrates
}

\author{
G.Collier, A. McLean and K. O'Dea* \\ Baker Medical Research Institute, Prahran, Victoria, Australia
}

\begin{abstract}
Summary. The present study examined the acute effects of coingestion of fat $(37.5 \mathrm{~g})$ on the post-prandial metabolic responses to $75 \mathrm{~g}$ of carbohydrate which was either slowly absorbed (lentils) or rapidly absorbed (potatoes). Co-ingestion of fat resulted in a significant flattening of the post-prandial glucose curves, the effect being more pronounced for the rapidly absorbed potatoes. This was probably due to delayed gastric emptying. However, the post-prandial insulin responses to either carbohydrate were not significantly reduced by fat, suggesting that the insulin response to a given glucose concentration was potentiated in the presence of fat. The gastric inhibitory polypeptide (GIP) responses to both carbohydrates were greatly increased in the presence of fat. To investigate further the possible roles of GIP in the entero-insular axis, a 5-g bolus of glucose was injected intravenously $1 \mathrm{~h}$ after lentils \pm fat. This was sufficient to raise the glucose levels above the thresh-
\end{abstract}

old reported for GIP to potentiate insulin secretion. However, despite the large differences in circulating GIP levels, the insulin response to glucose was not affected by the presence of fat. These results suggest that (1) the rate of absorption of carbohydrate is a major determinant of post-prandial metabolic responses even in the presence of fat, (2) fat-stimulated GIP secretion does not potentiate glucose-induced insulin secretion, and ( 3 ) the potentiation of the insulin response to glucose when carbohydrate is co-ingested with fat is consistent with the well-documented insulin resistance associated with high fat diets.

Key words: Insulin, gastric inhibitory polypeptide, insulin sensitivity, glucose tolerance, diabetes, diet, fat, rate of carbohydrate digestion.
Several studies have demonstrated the beneficial effects of high-carbohydrate, high-fibre diets in the treatment of Type 2 (non-insulin-dependent) diabetes $[1,2]$. The mechanism by which this dietary regimen improves long-term diabetic control remains unclear: is it due to the high complex carbohydrate, high fibre, type of fibre or low fat contents of such diets? Most previous studies have concentrated on the acute responses to complex carbohydrate and fibre components of the diet [3-5], and have highlighted the importance of rate of intestinal digestion and absorption in determining the metabolic responses to different carbohydrates. It has been suggested that these acute metabolic changes form the basis of long-term benefits associated with high-carbohydrate, high-fibre diets.

However, as these diets are also low in fat, and insulin sensitivity has been demonstrated to be inversely related to the fat content of the diet [6,7], it is possible that

\footnotetext{
* Present address: University of Melbourne, Department of Medicine, Repatriation General Hospital, Heidelberg West, Victoria, 3081, Australia
}

the improved metabolic control is due (at least in part) to the low fat content. Thus, the aim of the present study was to examine the acute interaction of two components of the high-carbohydrate, high-fibre diet: slowlyabsorbed carbohydrate, and fat. The effect of co-ingestion of fat on the post-prandial glucose, insulin and GIP responses to a rapidly-absorbed carbohydrate (potato) and a slowly-absorbed carbohydrate (lentils) [8] was measured. The secretion of GIP is greatly stimulated by fat ingestion as well as glucose and has been implicated in the entero-insular axis [9-13]. This study compared the different contributions that GIP stimulated by carbohydrate alone, or by carbohydrate together with fat, would have on the potentiation of insulin secretion.

\section{Materials and methods}

\section{Subjects}

Seven lean subjects (five men, two women), stable in weight, participated in the study. Their mean age was $23.4 \pm 3.7$ years, weight $65.7 \pm 4.9 \mathrm{~kg}$ and body mass index $22.0 \pm 0.6 \mathrm{~kg} / \mathrm{m}^{2}$. During the study 
the subjects were on a weight-maintaining diet which included at least $250 \mathrm{~g}$ of carbohydrate each day. The studies were performed on an outpatient basis after a 12-h overnight fast. This study was carried out in accord with the updated Helsinki Declaration and was approved by the Ethics Committee of the Alfred Hospital, Prahran, Victoria, Australia.

\section{Metabolic studies}

Six test meals were consumed in random order: $75 \mathrm{~g}$ carbohydrate (as $438 \mathrm{~g}$ potato or $121 \mathrm{~g}$ lentils) with or without $37.5 \mathrm{~g}$ fat (as $46.5 \mathrm{~g}$ butter); or $75 \mathrm{~g}$ carbohydrate (lentils) with or without $37.5 \mathrm{~g}$ fat with a $5-\mathrm{g}$ IV bolus injection of glucose $60 \mathrm{~min}$ after commencing the meal. The meals were prepared freshly on the morning of the study and were consumed within $10 \mathrm{~min}$. Zero time was taken as the time eating commenced. Blood samples were drawn for glucose, insulin and GIP measurements in the fasting state and at $0.25,0.5,1,1.5,2,3$ and $4 \mathrm{~h}$ post-prandially. In the case of the lentil \pm fat meals with the IV injection of glucose, additional blood samples were drawn at 65,70 and $75 \mathrm{~min}$.

\section{Analytical methods}

Samples for plasma glucose measurements were collected in fluoride oxalate tubes and analyzed by the glucose oxidase method using a YSI model 23AM glucose analyzer (Yellow Springs Instruments, Ohio). Plasma immunoreactive insulin concentrations in heparinized plasma were measured using dextran-coated charcoal for precipitation of free hormone with commercially available anti-insulin serum (Burroughs-Wellcome, UK). Human insulin (Novo) was used as a standard. Blood samples for GIP measurements were collected in heparinized tubes containing $3 \mathrm{mg}$ aprotinin (Trasylol) per $10 \mathrm{ml}$ blood.

Immunoreactive GIP concentrations in plasma were measured by double-antibody radioimmunoassay [14]. This antiserum exhibited $<1 \%$ cross reactivity with cholecystokinin, insulin, pancreatic polypeptide, pancreatic glucagon, porcine gut 'glucagon-like' immunoreactivity, secretin or vasoactive intestinal polypeptide.

\section{Data analysis}

Three-way analysis of variance was performed to compare the overall levels of glucose, insulin and GIP following consumption of different meals. Paired t-test and Student's t-test were used for statistical comparisons of peak heights and incremental areas under the glucose and insulin response curves.

\section{Results}

The glucose and insulin responses to the four test meals are shown in Figure 1. The glucose response to potatoes was significantly greater than the glucose response to lentils (analysis of variance, $p<0.01$ ). The co-ingestion of fat with potatoes significantly reduced the blood glucose response (analysis of variance, $p<0.05$ ), and although quantitatively smaller there was a similar trend when fat was eaten with lentils (analysis of variance, $p<0.05$ ).

The insulin response to potatoes was significantly greater than that to lentils (analysis of variance, $p<$ 0.01 ). In contrast to the effect on the glucose response, co-ingestion of fat with potatoes did not significantly reduce the post-prandial insulin response, and although there was a trend in this direction (at 30 and $60 \mathrm{~min}$ ),

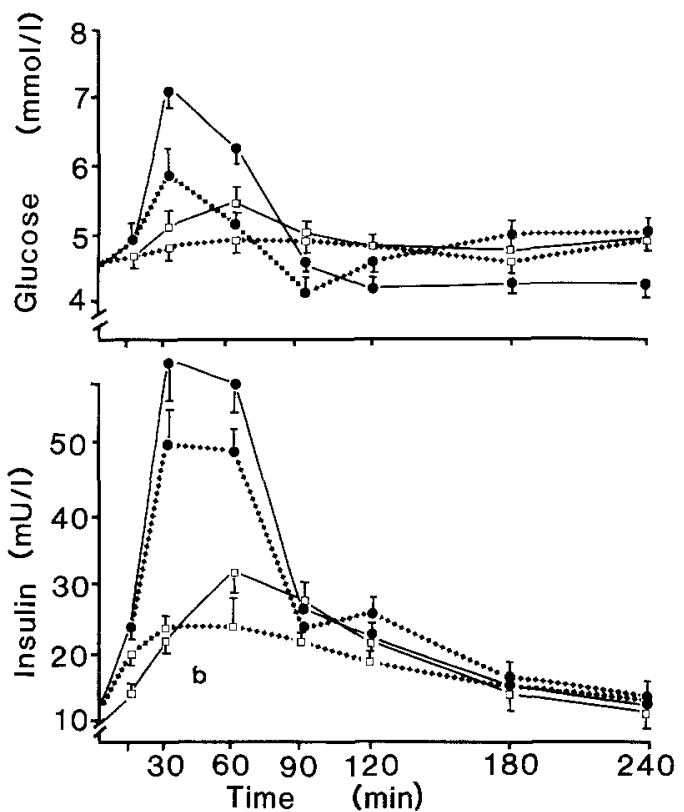

Fig. 1. Plasma glucose and insulin responses to $75 \mathrm{~g}$ carbohydrate given in the form of potatoes in the presence (-............. ) and absence (- $)$ of fat or as lentils in the presence $(\square \cdots \cdots . . . . . . . \square)$ and absence $(\square \square \square$ ) of fat (mean \pm SEM, $n=7$ ). The response curves were compared by three-way analysis of variance: glucose: potato $>$ lentils $(p<0.01)$, potato $>$ potato + fat $(p<0.05)$, lentils $>$ lentils + fat $(p<0.05)$; insulin: potato $>$ lentils $(p<0.01)$

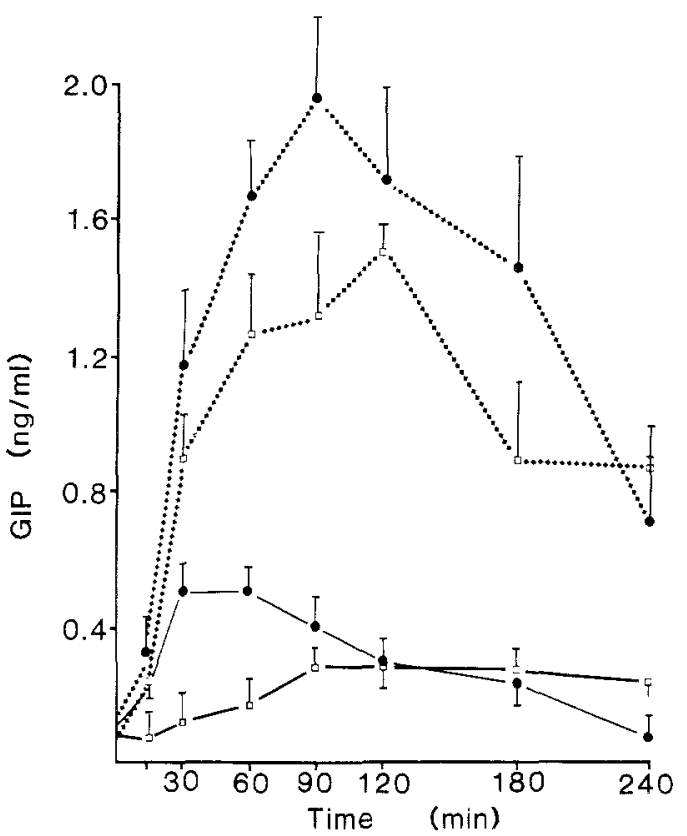

Fig. 2. Plasma GIP responses to $75 \mathrm{~g}$ carbohydrate given in the form of potatoes in the presence $(0 . . . . . . . . . . .6)$ and absence $(-\infty)$ ) of fat or as lentils in the presence $(\square \cdots \cdots \cdots \cdots \cdot \cdots)$ and absence $(\square \square \square)$ of fat (mean $\pm \operatorname{SEM}, n=7$ ). The response curves were compared by three-way analysis of variance: potato $>$ lentils $(p<0.01)$, potato + fat $>$ potato $(p<0.01)$, lentils + fat $>$ lentils $(p<0.01)$

differences were not significant whether by paired t-test at any of the time points or by analysis of variance. The insulin response to lentils and fat also tended to be lower but was not statistically different from that to lentils alone (using paired t-test and analysis of variance). This 

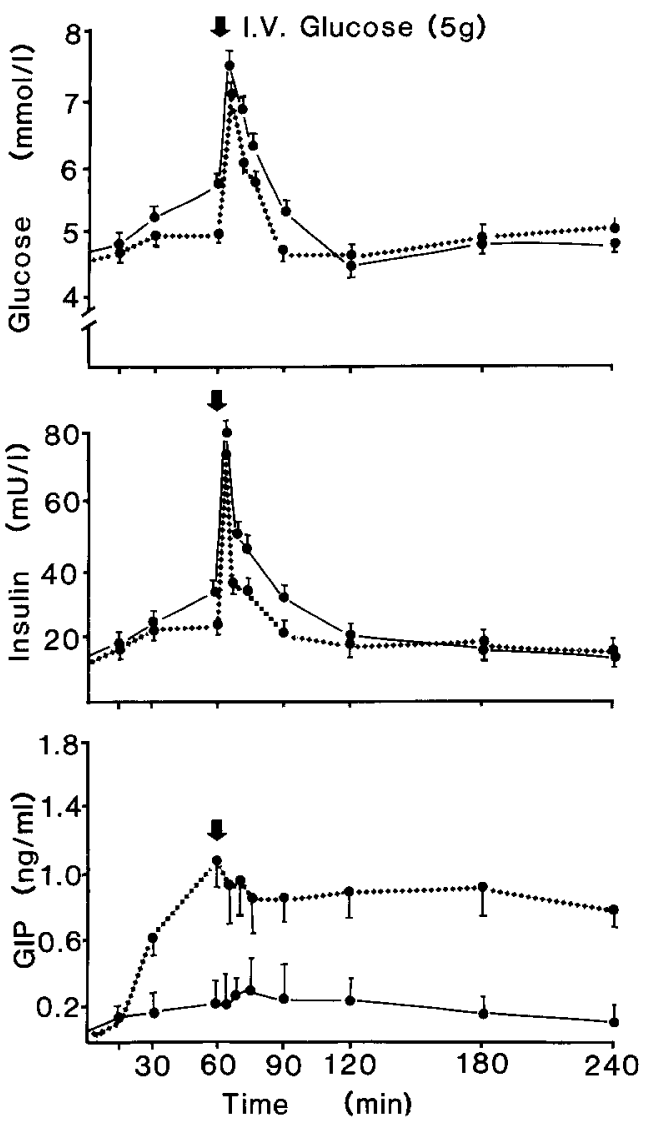

Fig.3. Plasma glucose, insulin and GIP responses to $75 \mathrm{~g}$ carbohydrate ingested orally as lentils at zero time in the presence (.................) and absence $\longrightarrow$ of fat, with the intravenous injection of $5 \mathrm{~g}$ glucose at $60 \mathrm{~min}$ (mean $\pm \mathrm{SEM}, n=7$ ). Peak levels $(65 \mathrm{~min})$ were compared using paired t-test. Glucose and insulin responses were not significantly different. GIP: lentils and fat $>$ lentils $(p<0.001)$

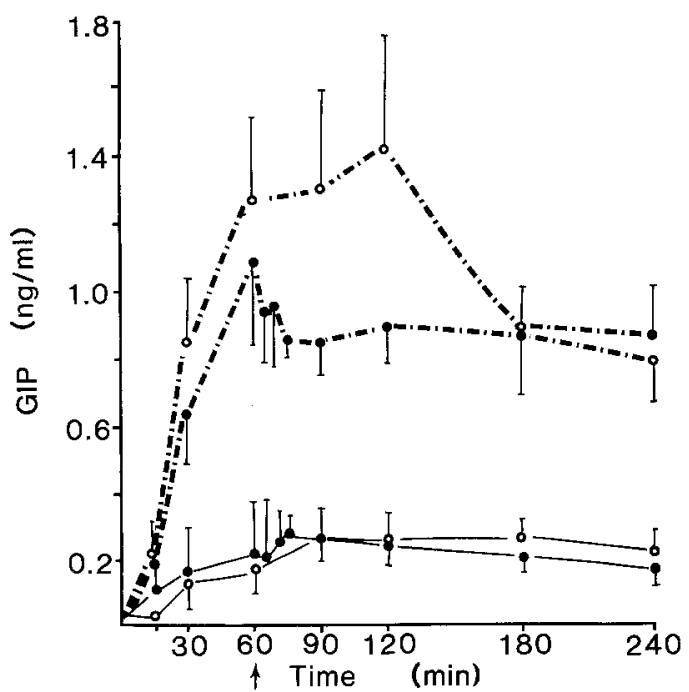

Fig.4. Plasma GIP responses to $75 \mathrm{~g}$ carbohydrate ingested orally as lentils in the presence (broken lines) or absence (solid lines) of fat, with $(-)$ or without $(O)$ the intravenous injection of $5 \mathrm{~g}$ glucose at 60 min (mean $\pm \mathrm{SEM}, n=7$ ). Individual paired points were compared using the paired t-test: lentils + fat $>$ lentils + fat + IV glucose: 65 min $(p<0.05), 70 \mathrm{~min}(p<0.05), 75 \mathrm{~min} \quad(p<0.01), 90 \mathrm{~min} \quad(p<0.01)$ $120 \min (p<0.05)$ is illustrated more clearly by comparing the incremental areas under the insulin response curves: potatoes alone, $3333 \pm 590 \mathrm{mU} \cdot 1^{-1} \cdot \mathrm{min}$; potatoes and fat, $3024 \pm$ $452 \mathrm{mU} \cdot 1^{-1} \cdot \min$; lentils, $1796 \pm 333 \mathrm{mU} \cdot 1^{-1} \cdot \min$; lentils and fat, $1324 \pm 256 \mathrm{mU} \cdot 1^{-1} \cdot \mathrm{min}$. When these results are expressed as a ratio of incremental area under the curve of insulin to that of glucose, the effect of fat on the insulin response to glucose becomes even more striking: insulin area/glucose area $=28.7 \pm 9.0$ for potato alone and $97.5 \pm 12.4$ for potato and fat; $27.2 \pm$ 8.7 for lentils alone and $41.4 \pm 5.3$ for lentils and fat.

The GIP responses to the four test meals are shown in Figure 2. The GIP response to potatoes was significantly higher than that to lentils (analysis of variance, $p<0.01$ ). Co-ingestion of fat gave rise to a significantly higher GIP response with both lentils and potatoes (analysis of variance, $p<0.01$, in both cases).

The effects of the IV injection of a 5-g glucose bolus one hour after the ingestion of lentils in the presence and absence of fat are presented in Figure 3 . The changes in plasma glucose and insulin in response to the bolus were rapid and not influenced by whether fat had or had not been consumed with the carbohydrate load. The 5-g glucose bolus was sufficient to raise the plasma glucose concentration by $2 \mathrm{mmol} / 1$, making it equivalent to the peak concentrations reached after the potato meal. However there was no potentiation of insulin response to the glucose bolus after the fatty meal. Figure 4 compares the GIP responses to lentils in the presence and absence of fat when the 5 -g bolus of glucose was injected intravenously one hour after the meals. The bolus injection significantly inhibited the GIP response to lentils and fat $(p<0.01)$, but had no effect on the GIP response to lentils alone, although the GIP levels after lentils were very low.

\section{Discussion}

The addition of fat to a carbohydrate meal significantly reduced the post-prandial glucose levels. The glucoselowering effect of fat was evident after co-ingestion with either potatoes or lentils. However, because of the smaller glycaemic response, the effect was quantitatively smaller when fat was co-ingested with lentils. Although an increased hepatic extraction of glucose in the presence of fat may occur, the most likely explanation for the decreased glucose response in the presence of fat is a delayed rate of gastric emptying which results in a reduced rate of carbohydrate absorption [15].

The glucose, insulin and GIP responses to the lentils alone were significantly lower than the response to potatoes. This confirms previous observations [8, 16-20] and supporting the concept of a direct relationship between the rate of carbohydrate absorption and glycaemic response, GIP release and insulin secretion. In this context it is important to note that, despite the lower glycaemic response when fat was co-ingested with pota- 
toes, the post-prandial insulin response was not significantly reduced. In other situations where blood glucose responses to carbohydrate meals have been reduced the insulin responses were reduced in a parallel fashion [3, 4]. For example, addition of a viscous fibre supplement (guar) to a glucose load resulted in a $46 \%$ decrease in post-prandial glucose and a 70\% decrease in incremental post-prandial insulin (3), while grinding rice before it was eaten resulted in a $140 \%$ increase in post-prandial glucose and a $130 \%$ increase in post-prandial insulin relative to the responses observed following ingestion of whole rice [4]. That the insulin levels have been maintained despite decreased blood glucose levels in the present study suggests that either the insulin response was potentiated after the co-ingestion of fat or there was a decrease in the insulin sensitivity. It is possible that these acute findings may provide insight into the longterm changes in insulin sensitivity which accompany alteration in dietary fat intake. Although the co-ingestion of fat with lentils gave results qualitatively similar to those observed with potatoes, the effect was quantitatively smaller, suggesting that even in the presence of fat the rate of absorption of the carbohydrate load remains one of the major determinants of acute post-prandial blood glucose and insulin responses.

In view of the reported insulinogenic role of GIP $[11,12]$ it was possible that the increased GIP response after the co-ingestion of carbohydrate and fat may have potentiated the insulin responses. In order to investigate further the role of the increased GIP levels in insulin secretion, 5-g IV glucose injections were given $1 \mathrm{~h}$ after the oral ingestion of lentils with or without fat. The intravenous injection raised plasma glucose levels above the reported threshold necessary for GIP to potentiate insulin secretion [21]. However, the insulin response was not affected by co-ingestion of fat, despite large differences in GIP levels. These results indicate that the higher levels of GIP circulating $1 \mathrm{~h}$ after lentils were consumed together with fat did not potentiate insulin secretion even in the presence of elevated blood glucose levels. These observations are consistent with the suggestion that GIP is not the sole gut factor responsible for potentiating insulin secretion [22]. The intravenous injection of glucose lowered the high circulating GIP concentration following carbohydrate and fat but had no effect on the lower GIP levels following carbohydrate alone. This supports previous observations that fat-stimulated GIP secretion is suppressed by elevated glucose or endogenous insulin, but that carbohydrate-stimulated GIP secretion is not [11]. The results of the present study do not exclude the possibility that carbohydrate-stimulated GIP secretion plays a role in the entero-insular axis. However, the GIP released following the co-ingestion of fat does not appear to play a major role, if any, in the potentiation of insulin secretion. Instead, it may be involved in fat assimilation. A preliminary report demonstrating that GIP increased lipoprotein lipase activity in pre-adipocytes would support such a role [23].
No definitive conclusions can be drawn from this acute study on the mechanisms of action of a high-carbohydrate, low-fat diet in improving glucose tolerance and insulin sensitivity in the long-term. Further studies are necessary to elucidate whether the type of carbohydrate consumed or the amount of fat ingested is more important in determining long-term metabolic control of blood glucose and insulin levels. However, the maintained insulin response found in this acute study after the co-ingestion of fat with carbohydrate is consistent with, and may form the basis of, the well-documented long-term insulin resistance associated with high dietary fat intakes $[6,7]$.

Acknowledgements. This work was supported by a grant from the National Health and Medical Research Council of Australia to K.O'D. It formed part of the work towards a Ph. D. for G. Collier. GIP antiserum was a gift from Professor V. Marks, University of Surrey, Guildford, Surrey, UK

\section{References}

1. Anderson JW, Ward K (1978) Long-term effects of high carbohydrate, high fiber diets on glucose and lipid metabolism. A preliminary report on patients with diabetes. Diabetes Care 1: 77-82

2. Simpson RW, Mann JI, Eaton J, Moore RA, Carter R, Hockaday TDR (1979) Improved glucose control in maturity-onset diabetes treated with high carbohydrate-modified fat diet. Br Med J 1: $1753-1756$

3. Jenkins DJA, Wolever TMS, Leeds AR, Gasull MA (1978) Dietary fibre, fibre analogues and glucose tolerance: Importance of viscosity. Br Med J 1: 1392-1394

4. O'Dea K, Nestel, PJ, Antonoff L (1980) Physical factors influencing postprandial glucose and insulin responses to starch. Am J Clin Nutr 33: 760-765

5. Jenkins DJA, Wolever TMS, Taylor RH, Ghafari H, Jenkins AL, Barker H, Jenkins MJA. (1980) Rate of digestion of foods and postprandial glycaemia in normal and diabetic subjects. Br Med J 281: $14-17$

6. Himsworth HP (1935) The dietetic factor determining the glucose tolerance and sensitivity to insulin of healthy men. Clin Sci 2: 67-94

7. Beck-Nielsen H, Pedersen O, Schwartz Sorensen N (1978) Effects of diet on the cellular insulin binding and the insulin sensitivity in young healthy subjects. Diabetologia 15: 289-296

8. Jenkins DJA, Ghafari $H$, Wolever TMS, Taylor RH, Jenkins AL, Barker HM, Fielden H, Bowling AC (1982) Relationship between rate of digestion of foods and post-prandial glycaemia. Diabetologia 22: $450-455$

9. Dupre J, Ross SA, Watson D, Brown JC (1975) The stimulation of insulin secretion by gastric inhibitory polypeptide in man. $\mathrm{J}$ Clin Endocrinol Metab 37: 826-828

10. Pederson RA, Schubert HE, Brown JC (1975) Gastric inhibitory polypeptide. Its physiological release and insulinotropic action in the dog. Diabetes 24: 1050-1056

11. Pederson RA, Brown JC (1976) The insulinotropic action of gastric inhibitory polypeptide in the perfused isolated rat pancreas. Endocrinol 99: 780-785

12. Brown JC, Dryburg JR, Ross SA, Dupré J (1975) Identification and actions of gastric inhibitory polypeptide. Recent Prog Horm Res 31: 487-532

13. Falko JM, Crockett SE, Cataland S, Mazzaperri EL (1975) Gastric inhibitory polypeptide stimulated by fat ingestion. J Clin Endocrinol Metab 41: 260-265

14. Morgan LM, Morris BA, Marks V (1978) Radioimmunoassay of gastric inhibitory polypeptide. Ann Clin Biochem 15: 172-177 
15. Thomas EJ (1957) Mechanics and regulation of gastric emptying. Physiol Rev 37: 453-474

16. Jenkins DJA, Wolever TMS, Taylor RH, Barker HN, Fielden H (1980) Exceptionally low blood glucose response to dried beans: comparison with other carbohydrate foods. $\mathrm{Br}$ Med J 281: $578-580$

17. Morgan LM, Goulder TJ, Tsiolakis D, Marks V, Alberti KGMM (1979) The effect of unabsorbable carbohydrate on gut hormones. Modification of post-prandial GIP secretion by guar. Diabetologia 17:85-89

18. Jenkins DJA, Bloom SR, Albuqerque RH, Leeds AR, Sarson DL, Metz GL, Alberti KGMM (1980) Pectin and complications after gastric surgery. Normalisation of postprandial glucose and endocrine responses. Gut 21: 574-579

19. Collier G, O'Dea K (1982) Effect of physical form of carbohydrate on the postprandial glucose, insulin and gastric inhibitory polypeptide responses in Type 2 diabetes. Am J Clin Nutr 36: 10-14

20. Jenkins DJA, Wolever TMS, Taylor RH, Griffiths C, Ktrzminska K, Lawrie JA, Bennet CM, Goff DV, Sarson DL, Bloom SR (1982) Slow release dietary carbohydrate improves second meal tolerance. Am J Clin Nutr 35: 1339-1346
21. Anderson DK, Elahi D, Brown JC, Tobin JD, Andres R (1978) Oral glucose augmentation of insulin secretion. J Clin Invest 62 : 152-161

22. Sarson DL, Wood SM, Holder D, Bloom SR (1982) The effect of glucose-dependent insulinotropic polypeptide infused at physiological concentrations on the release of insulin in man. Diabetologia 22: 33-36

23. Eckel, RH, Fujimoto WY, Brunzell JD (1979) Gastric inhibitory polypeptide enhanced lipoprotein lipase activity in cultured preadipocytes. Diabetes 28: 1141-1142

Received: 21 March 1983

and in revised form: 15 August 1983

Dr. K.O'Dea

Department of Medicine

Repatriation General Hospital

West Heidelberg, Victoria 3081

Australia 